Inorganic single wall nanotubes of $\mathrm{SbPS}_{4-x} \mathrm{Se}_{\mathrm{x}}(0 \leq x \leq 3)$ with tunable bandgap

Christos D. Malliakas and Mercouri G. Kanatzidis

Department of Chemistry, Michigan State University,

East Lansing, MI 48824.

Supporting Information 


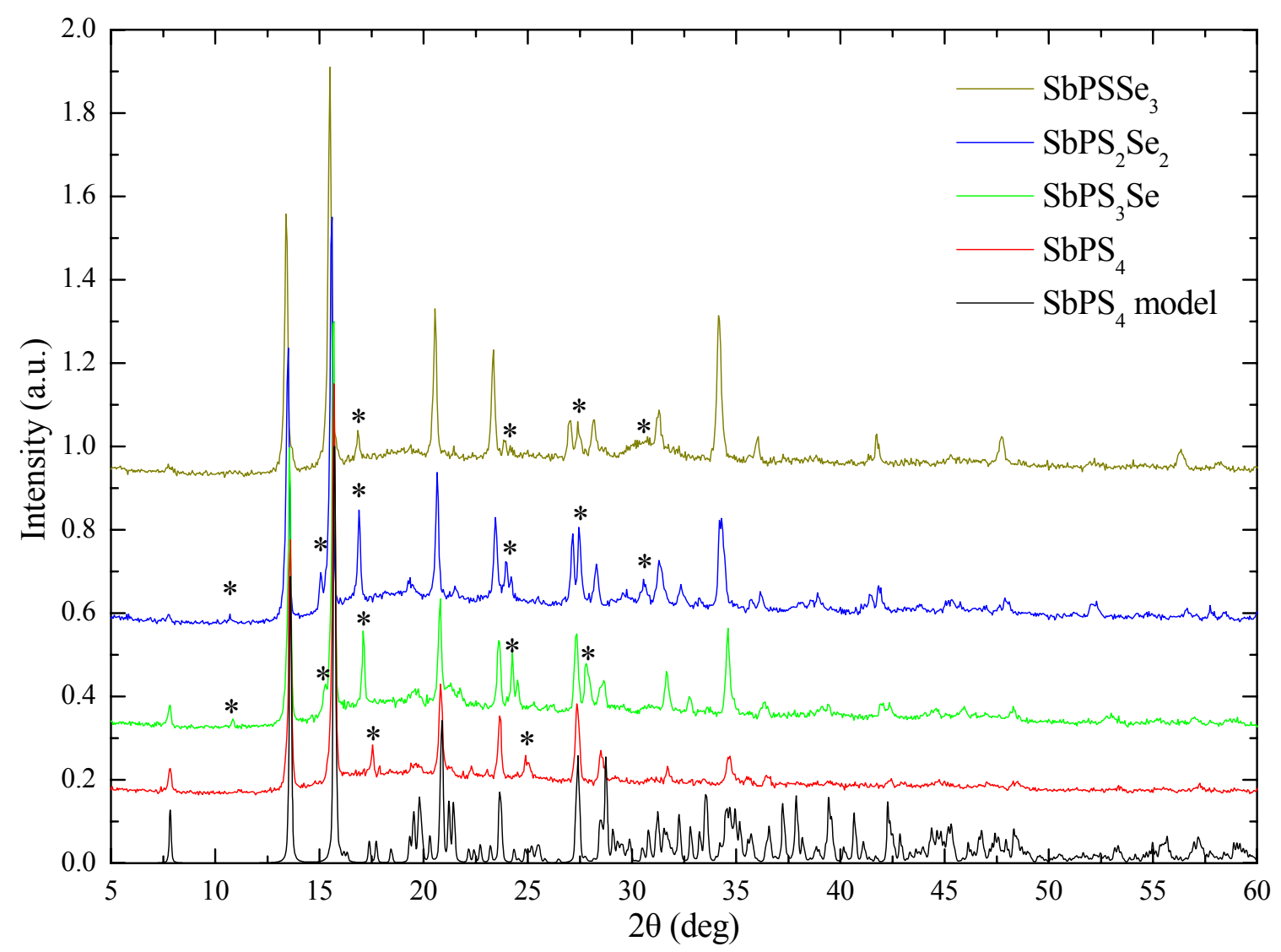

Figure 1S. Powder $x$-ray diffraction patterns of as-synthesized $\operatorname{SbPS}_{4-\mathrm{x}} \mathrm{Se}_{\mathrm{x}}(0 \leq \mathrm{x} \leq 3)$ series. $\mathrm{Sb}_{2} \mathrm{~S}_{3-\mathrm{x}} \mathrm{Se}_{\mathrm{x}}$ impurities are notated with *.

Table 1S. Refined cell constants for $\operatorname{SbPS}_{4-\mathrm{x}} \mathrm{Se}_{\mathrm{x}}(\mathrm{x}=0,1,2,3)^{(1)}$.

\begin{tabular}{ccccc}
\hline & $\mathrm{SbPS}_{4}$ & $\mathrm{SbPS}_{3} \mathrm{Se}$ & $\mathrm{SbPS}_{2} \mathrm{Se}_{2}$ & $\mathrm{SbPSSe}_{3}$ \\
\hline $\mathrm{a}(\AA)$ & $6.28(1)$ & $6.29(1)$ & $6.32(1)$ & $6.37(1)$ \\
$\mathrm{b}(\AA)$ & $13.05(2)$ & $13.10(2)$ & $13.14(2)$ & $13.24(2)$ \\
$\mathrm{c}(\AA)$ & $22.56(4)$ & $22.60(3)$ & $22.78(2)$ & $22.89(4)$ \\
$\alpha\left({ }^{\circ}\right)$ & $90.0(1)$ & $90.0(1)$ & $89.9(1)$ & $89.9(1)$ \\
$\beta\left({ }^{\circ}\right)$ & $90.3(2)$ & $90.6(2)$ & $90.5(2)$ & $90.6(2)$ \\
$\gamma\left({ }^{\circ}\right)$ & $91.9(2)$ & $92.1(3)$ & $91.9(2)$ & $91.8(3)$ \\
Volume $\left(\AA^{3}\right)$ & $1848(3)$ & $1861(2)$ & $1892(2)$ & $1928(3)$ \\
\hline
\end{tabular}

${ }^{(1)}$ Software used: T J B Holland and S A T Redfern ("Unit cell refinement from powder diffraction data: the use of regression diagnostics". Mineralogical Magazine, 1997, 61, 65-77. 


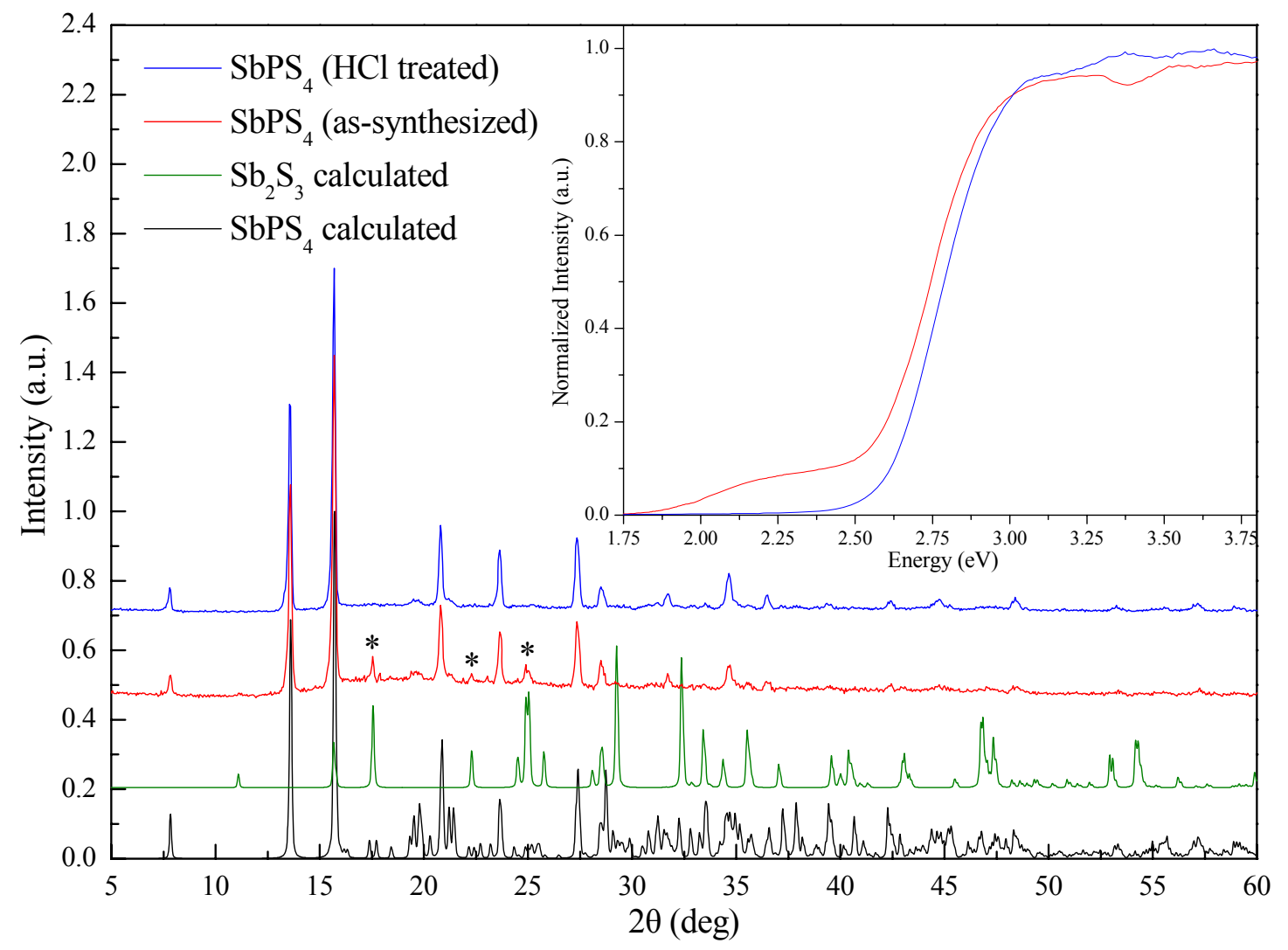

Figure 2S. Comparison of powder x-ray diffraction patterns of as-synthesized $\mathrm{SbPS}_{4}$ and $\mathrm{SbPS}_{4}$ soaked in concentrated $\mathrm{HCl}$. $\mathrm{Sb}_{2} \mathrm{~S}_{3}$ impurities are notated with *. Inset shows the comparison of optical band gap of the as-synthesized $\mathrm{SbPS}_{4}$ and $\mathrm{SbPS}_{4}$ treated with $\mathrm{HCl}$. The $\mathrm{Sb}_{2} \mathrm{~S}_{3}$ impurity gap around $1.8 \mathrm{eV}$ disappears after the acid wash. Impurities of $\mathrm{Sb}_{2} \mathrm{~S}_{3-\mathrm{x}} \mathrm{Se}_{\mathrm{x}}$ are not soluble in concentrated $\mathrm{HCl}$ for the case of the $\mathrm{SbPS}_{4-\mathrm{x}} \mathrm{Se}_{\mathrm{x}}$ analogues. Therefore, the tails in the optical measurements of the selenium containing $\mathrm{SbPS}_{4-\mathrm{x}} \mathrm{Se}_{\mathrm{x}}$ phases, Figure 3B, are most probably due to $\mathrm{Sb}_{2} \mathrm{~S}_{3-\mathrm{x}} \mathrm{Se}_{\mathrm{x}}$ impurities. 


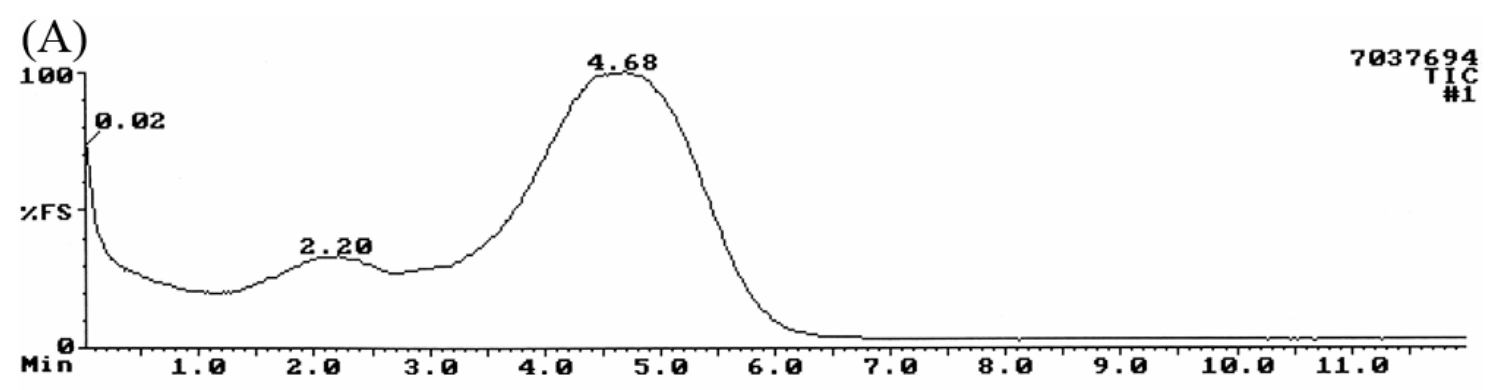

(B)
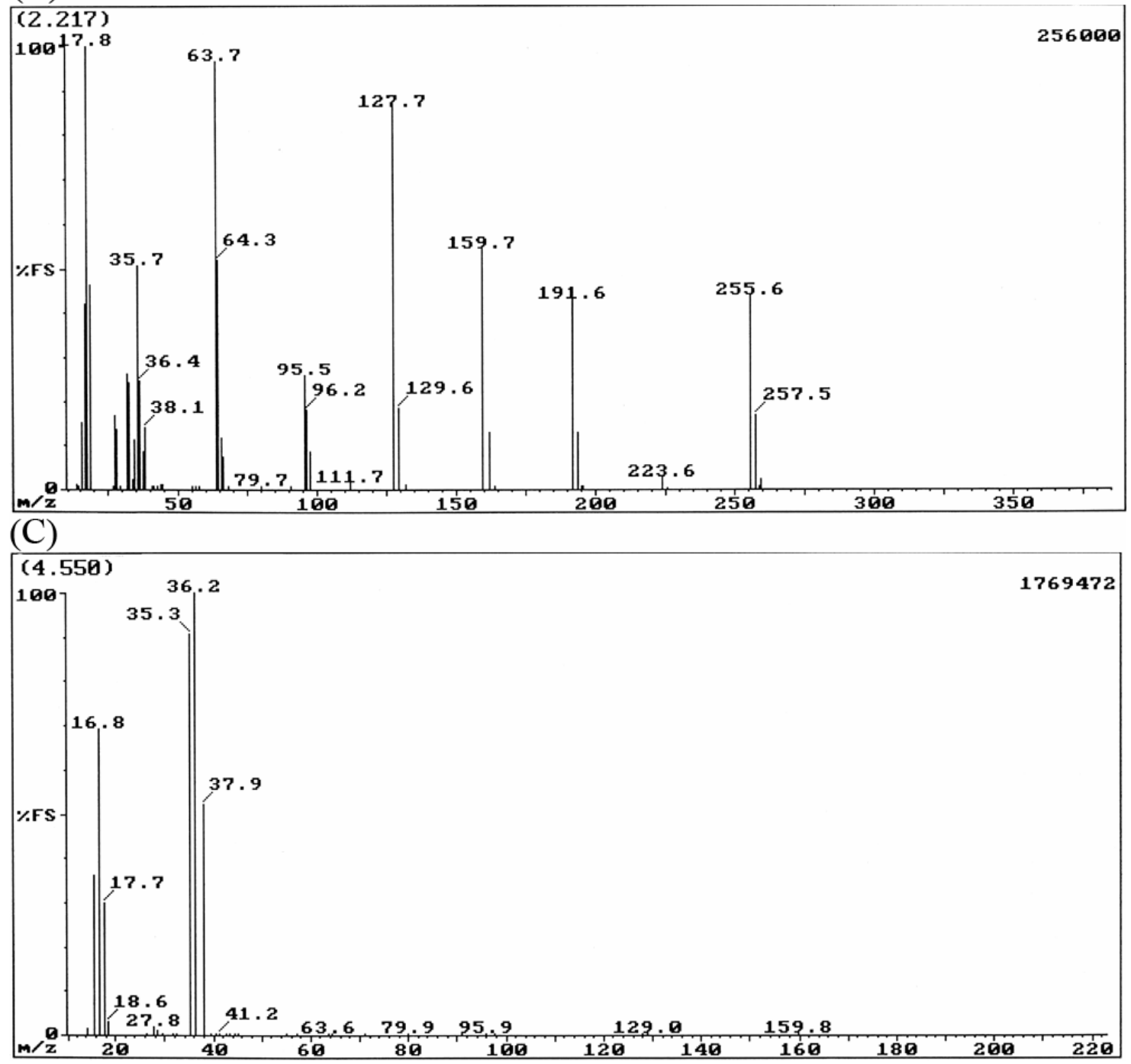

Figure 3S. (A) Plot of the total intensity of the ionic fragments for the acid treated $\mathrm{SbPS}_{4}$ from MS. The time scale is in minutes for a heating rate of $20^{\circ} \mathrm{C} / \mathrm{min}$ and a starting temperature of $30^{\circ} \mathrm{C}$ under vacuum $\left(\sim 10^{-5}\right.$ torr). (B) MS plot of the first peak at $\sim 2.2$ (74 $\left.{ }^{\circ} \mathrm{C}\right)$ shows the evaporation of $\mathrm{H}_{2} \mathrm{O}, \mathrm{HCl}$ and $\mathrm{S}_{\mathrm{x}}(1 \leq \mathrm{x} \leq 8)$ molecules. (C) MS plot of the second peak at $\sim 4.7\left(124^{\circ} \mathrm{C}\right)$ shows the evaporation of $\mathrm{H}_{2} \mathrm{O}$ and $\mathrm{HCl}$ molecules 


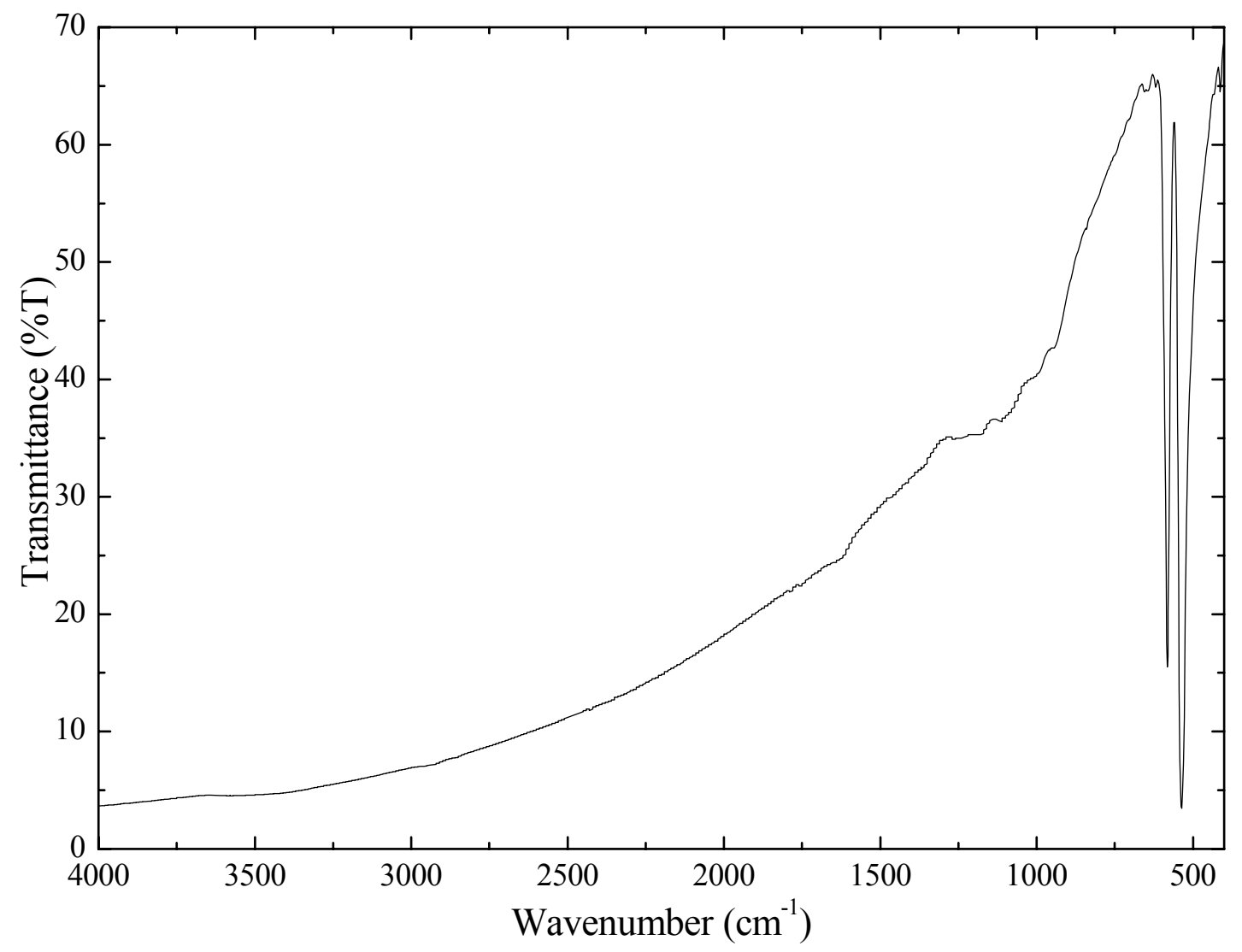

Figure 4S. Infrared spectrum of acid treated $\mathrm{SbPS}_{4}$ (transmission on $\mathrm{KBr}$ pellet). 


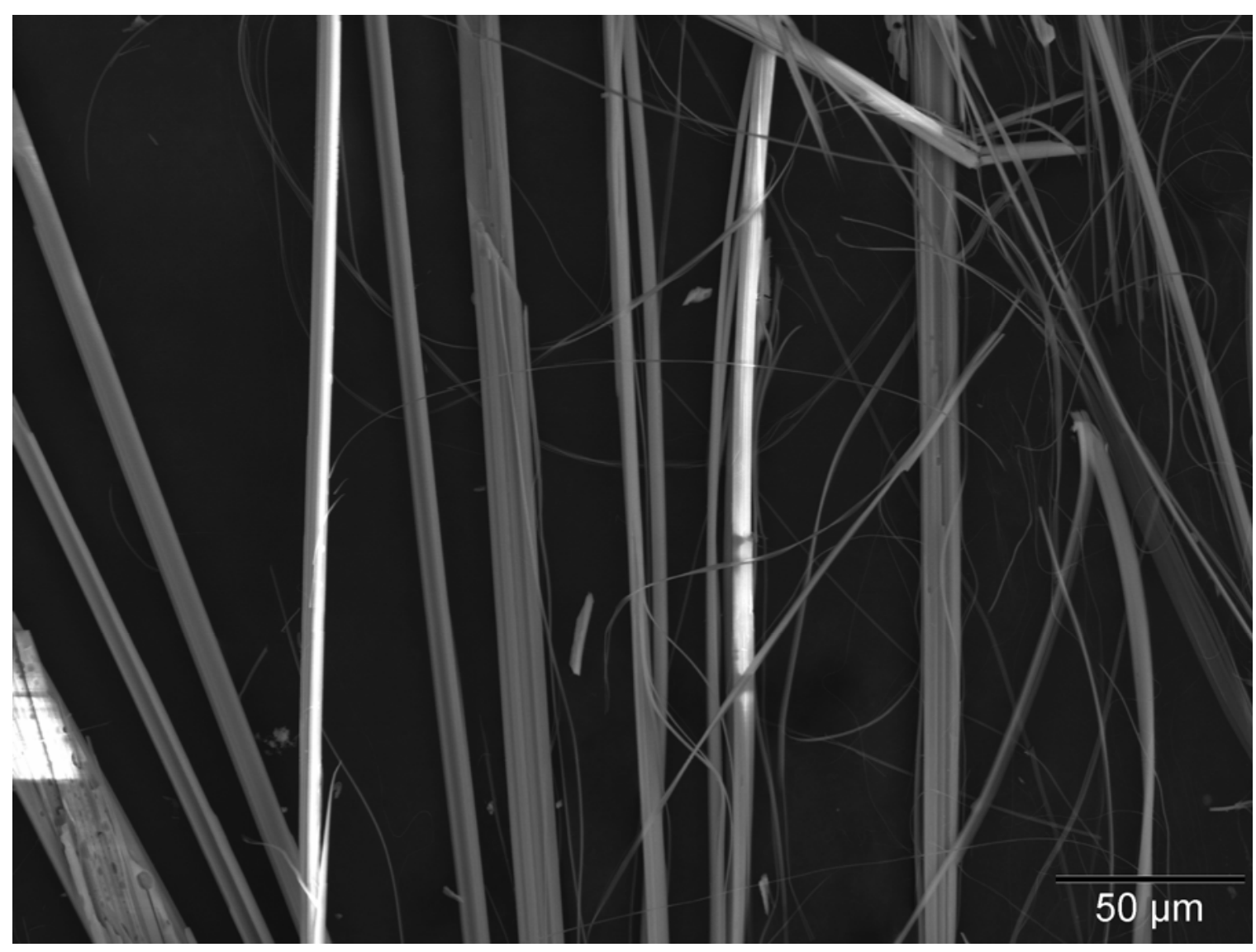

Figure 5S. SEM image of fibers of as-synthesized $\mathrm{SbPS}_{4}$. EDS analysis on few crystals confirms the relative ratio of 1:1:4 between Sb:P:S elements (within $\pm 4 \%$ ). 


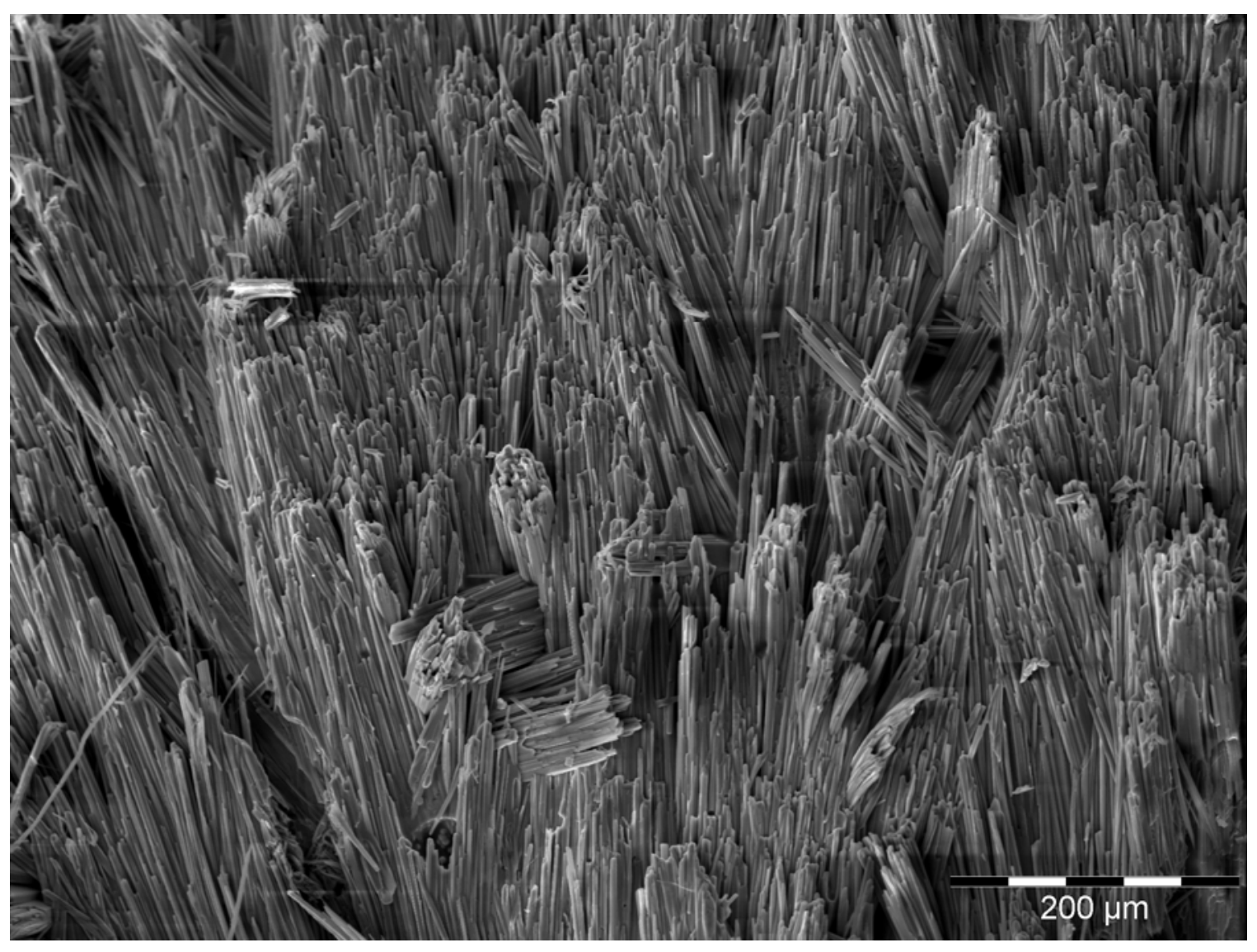

Figure 6S. SEM image of fibers of as-synthesized $\mathrm{SbPS}_{3} \mathrm{Se}$. EDS analysis on few crystals confirms the relative ratio of 1:1:3:1 between Sb:P:S:Se elements (within $\pm 4 \%$ ). 


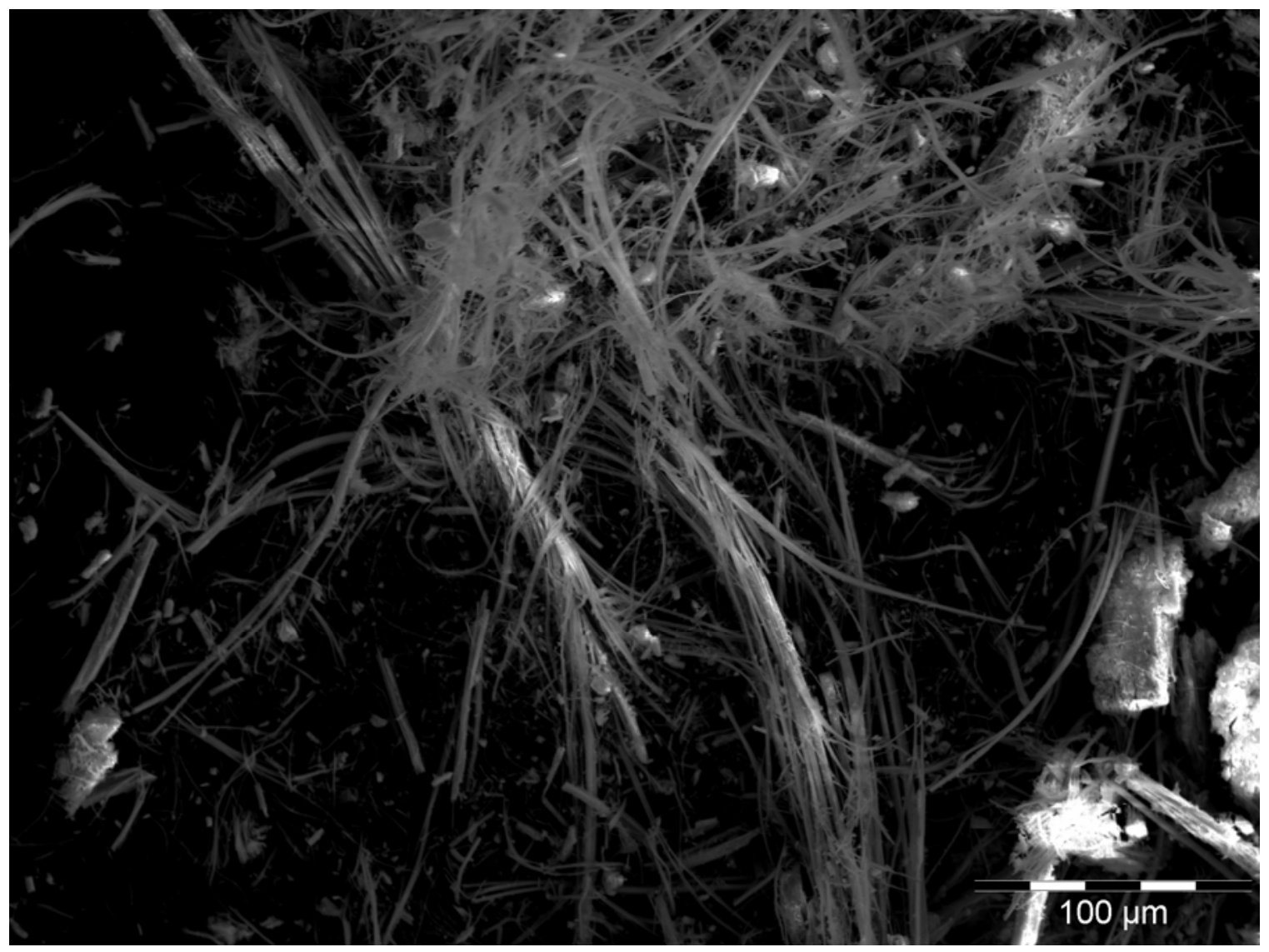

Figure 7S. SEM image of fibers of as-synthesized $\mathrm{SbPS}_{2} \mathrm{Se}_{2}$. EDS analysis on few crystals confirms the relative ratio of 1:1:2:2 between $\mathrm{Sb}: \mathrm{P}: \mathrm{S}:$ Se elements (within $\pm 4 \%$ ). 


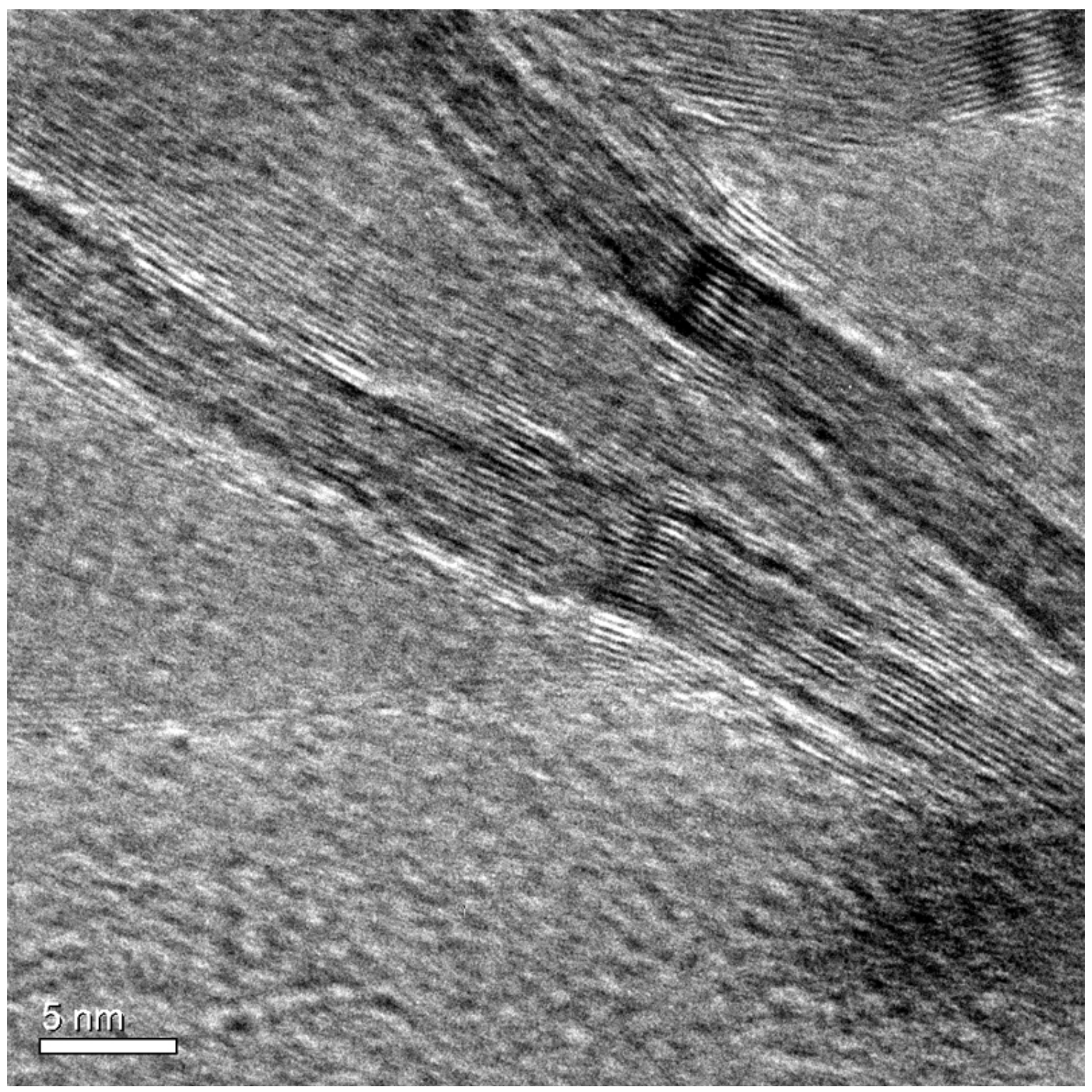

Figure 8S. HRTEM image of individual fiber bundles of $\mathrm{SbPS}_{4}$ after dispersion by sonication in DMF. EDS analysis on few fibers on the TEM grid confirms the relative ratio of 1:1:4 between Sb:P:S elements (within $\pm 4 \%$ ). 


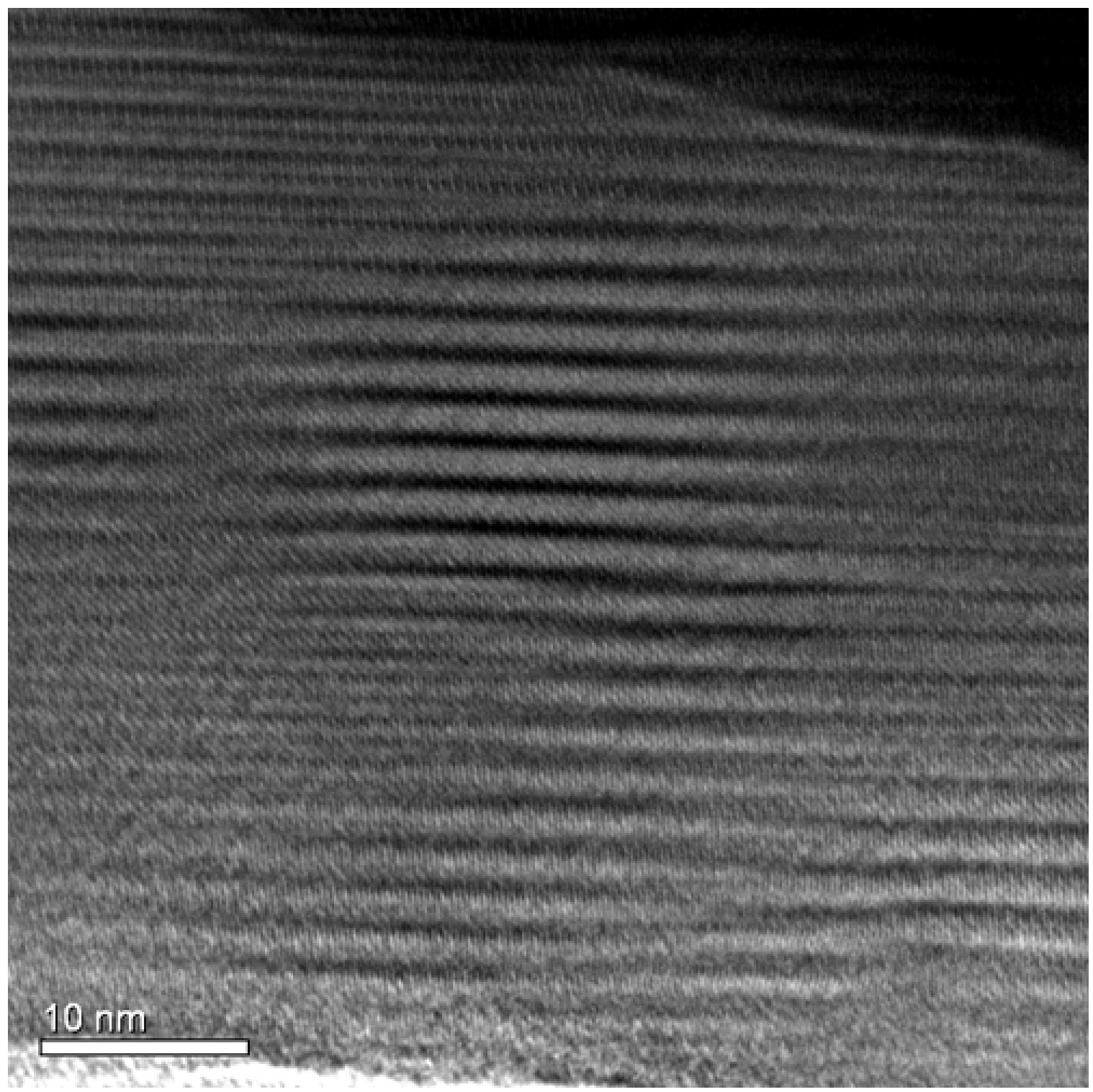

Figure 9S. HREM image of a $\mathrm{SbPS}_{4}$ bundle. Individual nanotubes are apparent at the center of the image with a diameter of $1.4 \mathrm{~nm}$. EDS analysis on few fibers on the TEM grid confirms the relative ratio of 1:1:4 between Sb:P:S elements (within $\pm 4 \%$ ). 


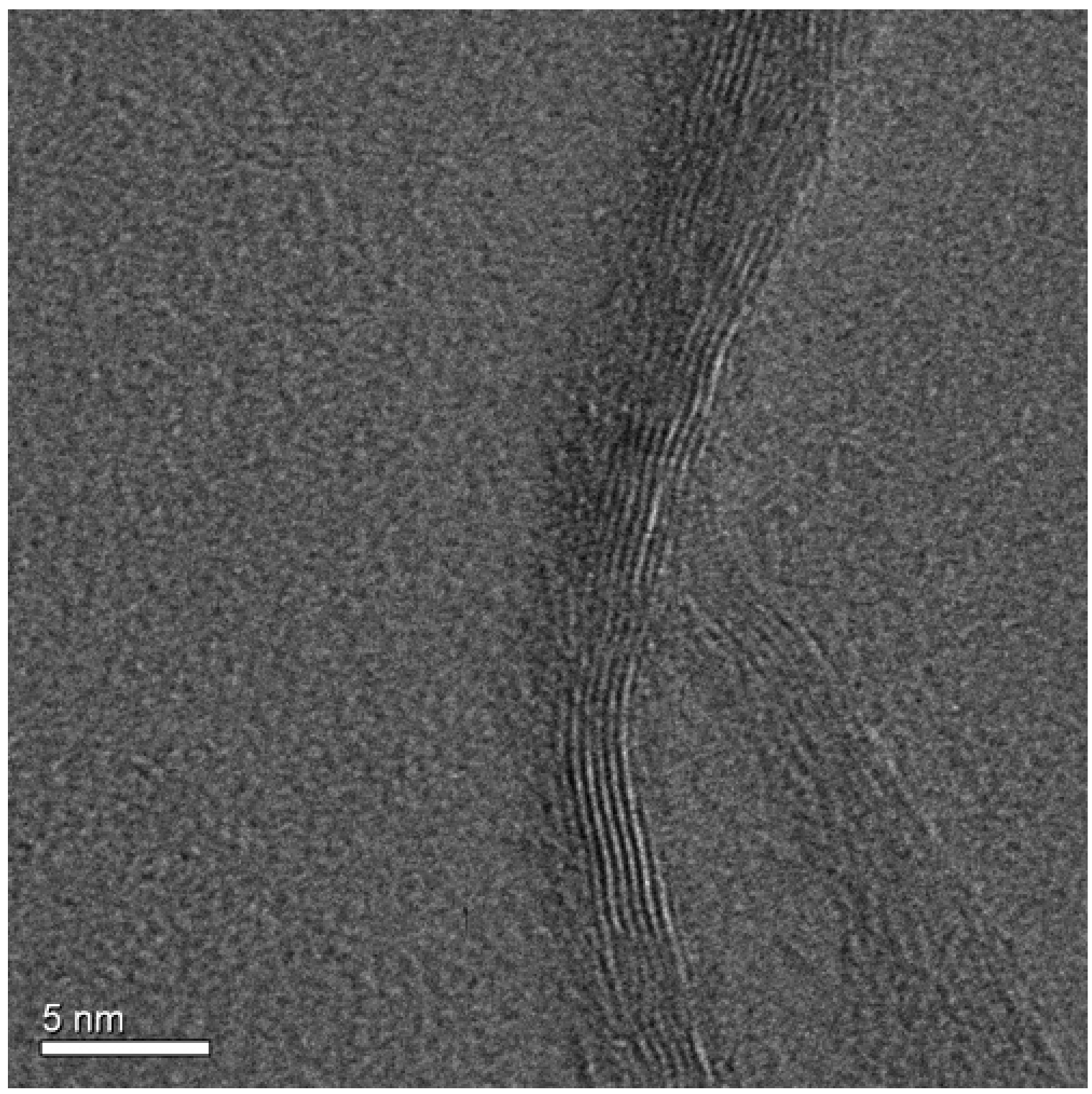

Figure 10S. HRTEM image of individual fiber bundles of $\mathrm{SbPS}_{4}$ after dispersion by sonication in DMF. EDS analysis on few fibers on the TEM grid confirms the relative ratio of 1:1:4 between Sb:P:S elements (within $\pm 4 \%$ ). 


\section{Electronic structure calculations}

Electronic structure calculations were performed using the self-consistent full-potential linearized augmented plane wave method (LAPW) ${ }^{1}$ within density functional theory $(\mathrm{DFT})^{2}$, using the generalized gradient approximation (GGA) of Perdew, Burke and Ernzerhof $^{3}$ for the exchange and correlation potential. The values of the atomic radii were taken to be: 1.7 a.u. for $\mathrm{P}$ atoms, 2.5 a.u. for $\mathrm{Sb}$ atoms and 2.0 a.u. for $\mathrm{S}$ atoms, where a.u. is the atomic unit $(0.529 \AA)$. Convergence of the self-consistent iterations was performed for $20 \mathrm{k}$ points inside the irreducible Brillouin zone to within 0.0001 Ry with a cutoff of 6.0 Ry between the valence and the core states. Scalar relativistic corrections were included and a spin-orbit interaction was incorporated using a second variational procedure. $^{4}$ The calculations were performed using WIEN2K program. ${ }^{5}$

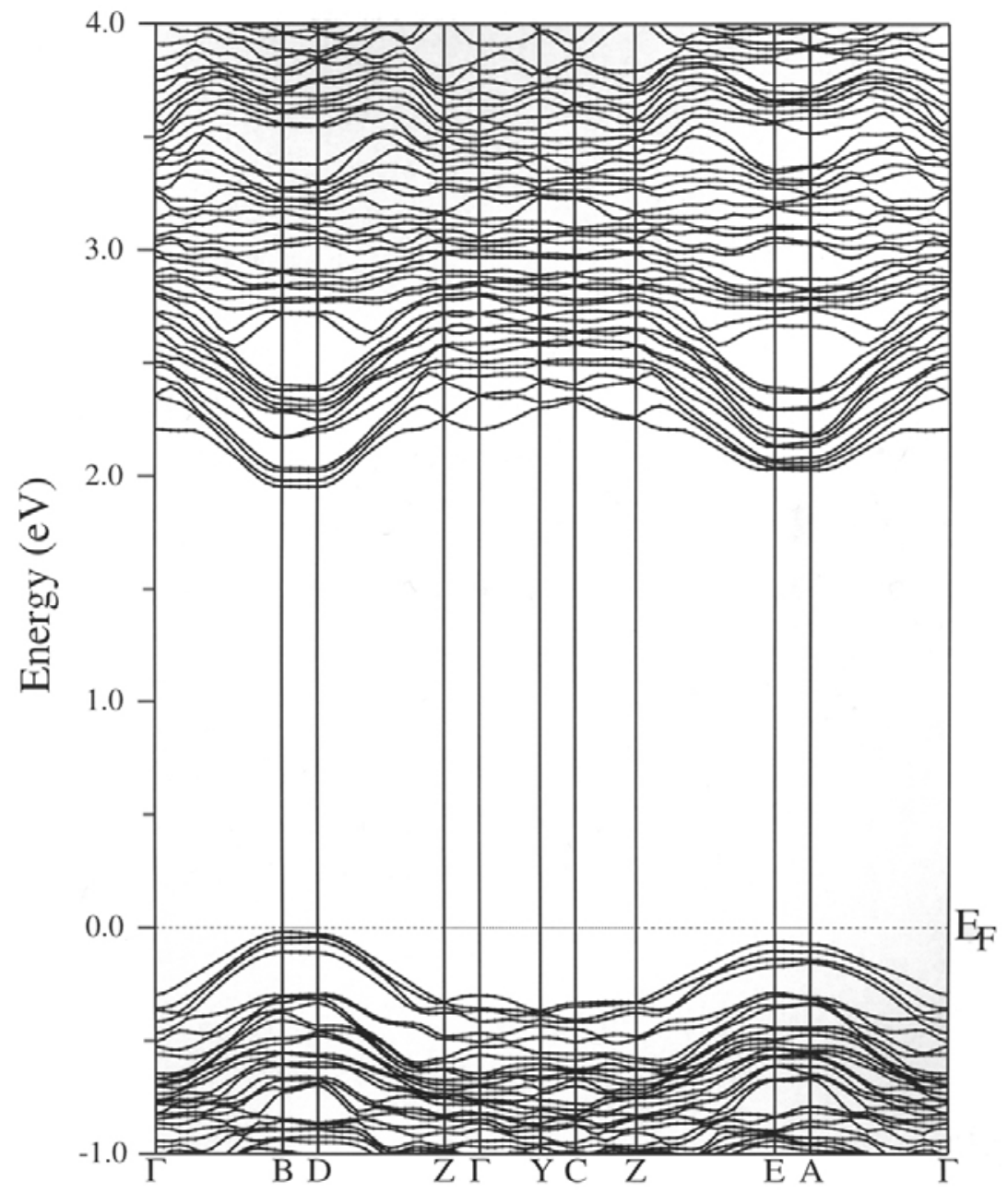

Figure 11S. Band structure of $\mathrm{SbPS}_{4}$ near the Fermi level. 
${ }^{1}$ Singh, D. Planewaves, Pseudopotentials, and the LAPW method; Kluwer Academic: Boston, MA, 1994.

2 (a) Hohenberg, P., Kohn, W., Phys. Rev., 1964, 136, B864-B871. (b) Kohn, W., Sham, L., Phys. Rev. 1965, 140, A1133-A1138.

${ }^{3}$ Perdew, J. P., Burke, K., Ernzerhof, M., Phys. Rev. Lett., 1996, 77, 3865-3868.

${ }^{4}$ Koelling, D. D., Harmon, B., J. Phys. C, 1977, 10, 3107

${ }^{5}$ Blaha, P., Schwarz, K., Madsen, G., Kvasnicka, D., Luitz ,J., WIEN2K, An Augmented Plane Wave + Local Orbitals Program for Calculating Crystal Properties; Karlheinz Schwarz, Tech. Univ.: Wien, Vienna, 2001. 